\title{
Study on temporalis fascia graft versus temporalis fascia with cartilage graft
}

\author{
A. Dayanand ${ }^{1}$, B. Harshavardhan ${ }^{2}$, J. Dheebika ${ }^{3}$, S. Palaninathan ${ }^{4}$ \\ ${ }^{1}$ Dr. A. Dayananad, DNB, Associate Professor, ${ }^{2}$ Dr. B. Harshavardhan, Senior Resident, ${ }^{3}$ Dr. J. Dheebika, \\ Postgraduate, ${ }^{4}$ Dr. S. Palaninathan, Head of Department, all authors are affiliated with PSGIMSR, Coimbatore, \\ MGR University, Tamil Nadu, India.
}

Corresponding Author: Dr. J. Dheebika, II Year Postgraduate, Department of Otorhinolaryngology, PSGIMSR, Coimbatore, MGR University, Tamil Nadu, India. E-mail: deepidee88@gmail.com

\begin{abstract}
Background: The aim of this analytical study is to compare the hearing improvement in type I Tympanoplasty between Temporalis Fascia used alone and temporalis Fascia with cartilage as graft material. Material and Methods: The study was done in ENT department at PSGIMSR, from October 2016 to July 2018. A total of 21,453 cases attended the ENT Outpatient department during the study period. Out of these, 75 cases with dry perforation of the tympanic membrane were chosen for the study. Patients were selected in random, excluding ear discharge, Attico-antral disease, and complications of chronic otitis media. Results: In the study population, disease afflicting the nose and throat were also ruled out. Detailed evaluation of each case was done comprising of history taking, clinical examination, investigations including pure tone audiometry. Patients were divided into 2 groups. Group A consist of 50 patients underwent type I Tympanoplasty with temporalis fascia alone. Group B consist of 25 patients underwent type I Tympanoplasty with combined Temporalis Fascia \& Conchal Cartilage. Post-operative hearing improvement measured by Audiometry is compared among the two groups and found that small perforations had best improvement with Temporalis Fascia graft, large and subtotal perforation had good improvement in postoperative hearing with combined Temporalis Fascia and Conchal Cartilage graft. Conclusion: Mean hearing improvement in Group A with temporalis graft was $12.98 \mathrm{~dB}$ (better) than Group B, with Temporalis Fascia \& Cochal Cartilage graft mean hearing improvement was $8.96 \mathrm{~dB}$.
\end{abstract}

Keywords: Temporalis Fascia, Conchal Cartilage, Type I Tympanoplasty.

\section{Introduction}

Tympanoplasty is done primarily to achieve a dry ear by eradicating middle ear disease and hearing improvement by closure of any Tympanic Membrane perforation by grafting with/without Ossicular reconstruction. The result of Tympanoplasty is measured by the success or failure of the graft uptake and hearing improvement. Various graft materials had been used by trial and error. These materials ranged from skin grafted from other areas of the body such as Thiersch graft, Split-skin graft, Pedicle graft from canal skin, Vein graft, Temporalis fascia graft, Scleral and Corneal graft, Perichondrial tissue, Cartilage [1-5]. Cartilage graft also provides firm support to prevent retraction formation. The greatest advantage of the Cartilage graft is its very low metabolic rate.

Manuscript received: $6^{\text {th }}$ October 2019

Reviewed: $16^{\text {th }}$ October 2019

Author Corrected: $21^{\text {st }}$ October 2019

Accepted for Publication: $26^{\text {th }}$ October 2019
Cartilage receives its nutrients by diffusion, is easy to work with because of its pliability, and its resistance to deformation from pressure variations.

Perichondrium and Cartilage [2] share with fascia the quality of being mesenchymal tissue. Cartilage are inherently thicker and stiffer compared to temporalis fascia. They mechanically reduce the vibratory pattern of the tympanic membrane in response to sound waves, contributing to some impairment in functional results.

This phenomenon is seen more in relation to higher tones. The mass effect of the cartilage over the prosthesis is always a concern. Cartilage has comparatively lower compliance than fascia. Cartilage is preferred in case of large or anteriorly placed perforations or associated eustachian tube dysfunction but at the cost of delayed hearing restoration for six months. 
Temporalis fascia is generally considered to be superior with respect to the take-up rate.

\section{Materials and Methods}

\section{Objective}

1. To assess the hearing outcome after Type-1 Tympanoplasty.

2. To compare the hearing improvement by the type of material used for graft

3. To evaluate the results of this study and compare it with similar studies

Study design: Analytical and follow up study.

Period of study: October 2016 to July 2018

Study population: Patients of 20-60 years age group.

Study area: Department of Otorhinolaryngology, PSGIMS\&R

Sample size: 5 Individuals.

Justification : This sample size correlates with the amount of patients with similar disease profile consulting at the ENT OPD

Subjects and selection method: 75 patients with perforated tympanic membrane due to Chronic Otitis Media, Trauma, recurrent middle ear infection presenting to ENT outpatient department at PSG IMS\&R will be taken up for study.

As soon as the patient presents to the hospital, detailed clinical history and examination will be carried out as per the proforma prepared. Laboratory investigations will be done. All patients will be subjected to preoperative Audiometric evaluation (PTA).

Type 1 Tympanoplasty will be done using different graft materials once the pre-operative investigations are noted and extent of disease established.

\section{Original Research Article}

Follow up with audiometric evaluations will be conducted at the end of $3^{\text {rd }}$ month following surgery and results will be compared with pre-operative Audiogram results

\section{Inclusion criteria}

Patients of age between 20 to 60 years presenting with

1. Perforated tympanic membrane due to Chronic Otitis media, Trauma, Recurrent middle ear infection

2. Intact ossicular chain

3. Dry ear

4. Intact Eustachian tube function

\section{Exclusion criteria}

1. Patients with Sensory neural hearing loss (SNHL)

2. CSOM with attico-antral type of disease.

3.Tympanosclerosis, middle ear Atelectasis, Middle ear tumours, Congenital Cholesteatoma.

\section{Potential benefits}

1. Improvement in hearing outcome of patients, will be helpful in proper diagnosis and better treatment of patients having conductive hearing loss.

2. Knowledge of the level of improvement of hearing and the rate of healing using different graft materials will be known.

\section{Risks}

1) Graft Failure

2) Minimal discomfort to the patient at the time of audiological testing performed post surgery.

\section{Method of collection of data}

Group A - 50 patients in which Temporalis Fascia was used as graft material

Group B- 25 patients in which Conchal Cartilage with fascia used as graft material

\section{Results}

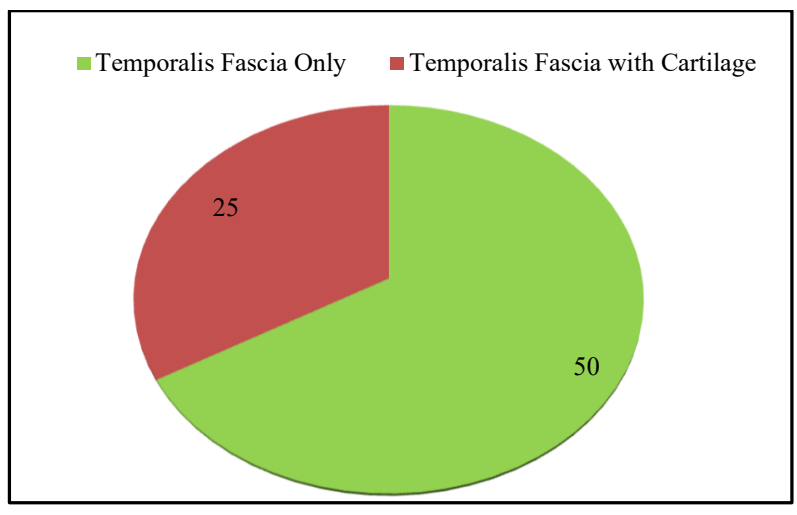

Figure 1: Distribution of graft material. 
In a total of 75 patients, temporalis fascia was used as graft material in 50 patients $(66.7 \%)$ and Conchal cartilage with fascia was used as graft in 25 patients (33.3\%) (Figure 1).

Table 1: Surgical Approach

\begin{tabular}{|c|c|c|c|c|c|}
\hline & & & \multicolumn{2}{|c|}{ Surgical approach } & \multirow[t]{2}{*}{ Total } \\
\hline & & & Endaural & Retroauricular & \\
\hline \multirow[t]{8}{*}{ Type of Perforation } & \multirow[t]{2}{*}{ Small } & No & 12 & 17 & 29 \\
\hline & & $\%$ & $41.4 \%$ & $58.6 \%$ & $100.0 \%$ \\
\hline & \multirow[t]{2}{*}{ Medium } & No & 2 & 24 & 26 \\
\hline & & $\%$ & $7.7 \%$ & $92.3 \%$ & $100.0 \%$ \\
\hline & \multirow[t]{2}{*}{ Large } & No & 0 & 16 & 16 \\
\hline & & $\%$ & $.0 \%$ & $100.0 \%$ & $100.0 \%$ \\
\hline & \multirow[t]{2}{*}{ Sub-total } & No & 0 & 4 & 4 \\
\hline & & $\%$ & $.0 \%$ & $100.0 \%$ & $100.0 \%$ \\
\hline \multirow{2}{*}{\multicolumn{2}{|c|}{ Total }} & No & 14 & 61 & 75 \\
\hline & & $\%$ & $18.7 \%$ & $81.3 \%$ & $100.0 \%$ \\
\hline
\end{tabular}

Retroauricular approach was used in 24 cases $(92.3 \%)$ with medium perforation of the tympanic membrane, which was the most. Endaural approach for surgery was used in 12 patients $(41.4 \%)$ with small perforations of the tympanic membrane, which was the most (Table 2).

Table-2: Type of perforation.

\begin{tabular}{|c|c|c|}
\hline & Frequency & Percent \\
\hline Small & 29 & 38.7 \\
\hline Medium & 26 & 34.7 \\
\hline Large & 16 & 21.3 \\
\hline Sub-total & 4 & 5.3 \\
\hline Total & 75 & 100.0 \\
\hline
\end{tabular}

In a total of 75 cases, small perforation of the tympanic membrane was present in 29 individuals $(38.7 \%)$ which was the highest. Subtotal perforation was present in 4 individuals $(5.3 \%)$ which was the low (Table 3$)$.

Table-3: Graft material

\begin{tabular}{|c|c|c|c|c|c|}
\hline & & & \multicolumn{2}{|c|}{ Surgical approach } & \multirow[t]{2}{*}{ Total } \\
\hline & & & Endaural & Retroauricular & \\
\hline \multirow[t]{8}{*}{ Type of Perforation } & \multirow[t]{2}{*}{ Small } & No & 12 & 17 & 29 \\
\hline & & $\%$ & $41.4 \%$ & $58.6 \%$ & $100.0 \%$ \\
\hline & \multirow[t]{2}{*}{ Medium } & No & 2 & 24 & 26 \\
\hline & & $\%$ & $7.7 \%$ & $92.3 \%$ & $100.0 \%$ \\
\hline & \multirow[t]{2}{*}{ Large } & No & 0 & 16 & 16 \\
\hline & & $\%$ & $.0 \%$ & $100.0 \%$ & $100.0 \%$ \\
\hline & \multirow[t]{2}{*}{ Sub-total } & No & 0 & 4 & 4 \\
\hline & & $\%$ & $.0 \%$ & $100.0 \%$ & $100.0 \%$ \\
\hline \multirow{2}{*}{\multicolumn{2}{|c|}{ Total }} & No & 14 & 61 & 75 \\
\hline & & $\%$ & $18.7 \%$ & $81.3 \%$ & $100.0 \%$ \\
\hline
\end{tabular}

Graft material used based on type of perforation- 29 Individuals had a small perforation of the tympanic membrane. Temporalis fascia was used in all 29 cases (100\%). In cases with medium perforation, 19 cases $(73.1 \%)$ had temporalis fascia as graft and 7 cases $(26.9 \%)$ had fascia with cartilage as graft.

In cases with large perforations, 2 cases $(12.5 \%)$ had temporalis fascia and 14 cases $(87.5 \%)$ had fascia with cartilage as graft. All 4 individuals $(100 \%)$ had cartilage with fascia as graft material in subtotal perforation. 
Table-4: Graft material used based on surgical approach.

\begin{tabular}{|c|c|c|c|c|c|}
\hline & & & \multicolumn{2}{|c|}{ Surgical approach } & \multirow[t]{2}{*}{ Total } \\
\hline & & & Endaural & Retroauricular & \\
\hline \multirow[t]{8}{*}{ Type of Perforation } & \multirow[t]{2}{*}{ Small } & No & 12 & 17 & 29 \\
\hline & & $\%$ & $41.4 \%$ & $58.6 \%$ & $100.0 \%$ \\
\hline & \multirow[t]{2}{*}{ Medium } & No & 2 & 24 & 26 \\
\hline & & $\%$ & $7.7 \%$ & $92.3 \%$ & $100.0 \%$ \\
\hline & \multirow[t]{2}{*}{ Large } & No & 0 & 16 & 16 \\
\hline & & $\%$ & $.0 \%$ & $100.0 \%$ & $100.0 \%$ \\
\hline & \multirow[t]{2}{*}{ Sub-total } & No & 0 & 4 & 4 \\
\hline & & $\%$ & $.0 \%$ & $100.0 \%$ & $100.0 \%$ \\
\hline \multirow{2}{*}{\multicolumn{2}{|c|}{ Total }} & No & 14 & 61 & 75 \\
\hline & & $\%$ & $18.7 \%$ & $81.3 \%$ & $100.0 \%$ \\
\hline
\end{tabular}

Out of the total 75 cases, both endaural and retroauricular approach for surgery was used. Temporalis fascia was used in 50 cases $(66.7 \%)$, out of which endaural approach and retroauricular approach was used in 14 cases and 36 cases respectively (Table 4$)$.

Temporalis fascia with cartilage graft was used in 25 cases $(33.3 \%)$ in which all cases were operated using retroauricular approach

Table-5: Correlation between post-operative hearing and graft material.

\begin{tabular}{|c|c|c|c|c|c|}
\hline \multicolumn{6}{|c|}{ Post-operative hearing $(\mathrm{db}) *$ Graft Material } \\
\hline & & & Grat & aterial & \multirow[b]{2}{*}{ Total } \\
\hline & & & $\begin{array}{l}\text { Temporalis } \\
\text { Fascia Only }\end{array}$ & $\begin{array}{l}\text { Temporalis } \\
\text { Fascia with } \\
\text { Cartilage }\end{array}$ & \\
\hline \multirow[t]{10}{*}{ Post-operative hearing (db) } & \multirow[t]{2}{*}{$0-10$} & No & 16 & 0 & 16 \\
\hline & & $\%$ & $100.0 \%$ & $.0 \%$ & $100.0 \%$ \\
\hline & \multirow[t]{2}{*}{$11-20$} & No & 28 & 0 & 28 \\
\hline & & $\%$ & $100.0 \%$ & $.0 \%$ & $100.0 \%$ \\
\hline & \multirow[t]{2}{*}{$21-30$} & No & 5 & 9 & 14 \\
\hline & & $\%$ & $35.7 \%$ & $64.3 \%$ & $100.0 \%$ \\
\hline & \multirow[t]{2}{*}{$31-40$} & No & 1 & 13 & 14 \\
\hline & & $\%$ & $7.1 \%$ & $92.9 \%$ & $100.0 \%$ \\
\hline & \multirow[t]{2}{*}{$41-50$} & No & 0 & 3 & 3 \\
\hline & & $\%$ & $.0 \%$ & $100.0 \%$ & $100.0 \%$ \\
\hline \multirow[t]{2}{*}{ Total } & & No & 50 & 25 & 75 \\
\hline & & $\%$ & $66.7 \%$ & $33.3 \%$ & $100.0 \%$ \\
\hline
\end{tabular}

Post-operative hearing when temporalis fascia was used as graft material was 11-20 dB in 28 individuals which was the highest and was lowest in 1 individual (7.1\%) with post-operative hearing of 31-40 dB (Table 5).

In the group in which cartilage with fascia was used, highest individuals was $13(92.9 \%)$, where the post-operative hearing was 31-40 dB. The post-operative hearing was 41-50 dB in 3 individuals which was the lowest. 
Table 5: Hearing improvement based on graft material.

\begin{tabular}{|c|c|c|c|c|c|}
\hline \multicolumn{6}{|c|}{ Post-operative hearing (db) * Graft Material } \\
\hline & & & \multicolumn{2}{|c|}{ Graft Material } & \multirow[t]{2}{*}{ Total } \\
\hline & & & $\begin{array}{l}\text { Temporalis } \\
\text { Fascia Only }\end{array}$ & $\begin{array}{c}\text { Temporalis } \\
\text { Fascia with } \\
\text { Cartilage }\end{array}$ & \\
\hline \multirow[t]{10}{*}{ Improvement (db) } & \multirow{2}{*}{$0-5$} & No & 4 & 5 & 9 \\
\hline & & $\%$ & $44.4 \%$ & $55.6 \%$ & $100.0 \%$ \\
\hline & \multirow{2}{*}{$6-10$} & No & 7 & 11 & 18 \\
\hline & & $\%$ & $38.9 \%$ & $61.1 \%$ & $100.0 \%$ \\
\hline & \multirow{2}{*}{$11-15$} & No & 26 & 9 & 35 \\
\hline & & $\%$ & $74.3 \%$ & $25.7 \%$ & $100.0 \%$ \\
\hline & \multirow{2}{*}{$16-20$} & No & 11 & 0 & 11 \\
\hline & & $\%$ & $100.0 \%$ & $.0 \%$ & $100.0 \%$ \\
\hline & \multirow{2}{*}{$21-25$} & No & 2 & 0 & 2 \\
\hline & & $\%$ & $100.0 \%$ & $.0 \%$ & $100.0 \%$ \\
\hline \multirow{2}{*}{\multicolumn{2}{|c|}{ Total }} & No & 50 & 25 & 75 \\
\hline & & $\%$ & $66.7 \%$ & $33.3 \%$ & $100.0 \%$ \\
\hline
\end{tabular}

When temporalis fascia alone was used as graft, Post-operative hearing improvement was observed in 26 individuals (74.3\%) with an improvement of 11-15 dB. In the group with fascia and cartilage graft, the highest individuals was 11 (61.1\%) with an improvement of 6-10 dB (Table 6).

The most improvement in hearing when temporalis fascia is used, was observed in 2 cases (100\%) with $21-25 \mathrm{~dB}$ of hearing improvement. 11-15 dB was the maximum improvement observed when fascia with cartilage was used in 9 cases $(25.7 \%)$.

Table 7: Post-operative hearing improvement.

\begin{tabular}{|l|c|c|c|}
\hline Improvement $(\mathrm{dB})$ & & & \\
\hline Graft Material & Mean & $\mathrm{N}$ & Std. Deviation \\
\hline Temporalis Fascia Only & 12.9800 & 50 & 4.20636 \\
\hline Temporalis Fascia with Cartilage & 8.9600 & 25 & 3.24654 \\
\hline Total & $\mathbf{1 1 . 6 4 0 0}$ & $\mathbf{7 5}$ & $\mathbf{4 . 3 3 2 9 0}$ \\
\hline
\end{tabular}

Mean hearing improvement in Group A was $12.98 \mathrm{~dB}$ and in Group B, mean hearing improvement was $8.96 \mathrm{Db}$ (Table 7).

\section{Discussion}

A total of 21,453 cases attended the ENT Outpatient department during the study period. Out of these, 75 cases with dry perforation of the tympanic membrane were chosen for the study. Patients were selected in random, excluding patients with active ear discharge, attico-antral disease, and complications of chronic otitis media. In the study population, disease afflicting the nose and throat were also ruled out.

Detailed evaluation of each case was done comprising of history taking, clinical examination, investigations. Pre-operative as well as hearing assessment after the patients underwent type-1 tympanoplasty was performed using underlay technique.
Tympanic membrane perforation: Tympanic membrane perforation was present in all 75 patients in the study. Ear discharge was not seen in any of the patients. Based on the quadrant of tympanic membrane involved, perforation was graded into small, medium, large and subtotal perforation. Perforation of the Pars Flaccida was ruled out in all 75 of the participants in this study [6-10].

In the present study of 75 participants, small perforation was seen in 29 cases $(38.6 \%)$, medium perforation was present in 26 cases $(34.6 \%)$, large perforation was present in 16 cases $(21.3 \%)$ and subtotal perforation was present in 4 cases $(5.3 \%)$. 
In a study done by Kshitij Patil [1], maximum number of cases had subtotal perforation, i.e., 59 cases $(49.17 \%)$, followed by large central perforation in 51 cases $(42.5 \%)$, while 10 cases $(8.33 \%)$ had total perforation.

Surgical approach: In the present study, both endaural and retroauricular approach were used for different patients. 61 patients $(81.3 \%)$ underwent surgery through retroauricular approach and 14 patients (18.7\%) underwent surgery by endaural approach.

In the study done by Ramagiri Vijay Kumar [11], in patients of group A $14(70 \%)$ were operated by postaural route, 5 patients $(25 \%)$ by permeatal route and 1 patient $(5 \%)$ by endaural route. 13 patients $(65 \%)$ of group B were operated using endaural route and 7 patients $(35 \%)$ by using postaural route. All the patients of group $\mathrm{C}$ were taken by permeatal route. So permeatal route was used in $63.3 \%$ of all cases.

Graft Material: The study participants of the present study were divided into two groups based on usage of graft material namely temporalis fascia alone and temporalis fascia used along with conchal cartilage. In the present study, 50 individuals $(60.66 \%)$ underwent type-1 tympanoplasty using temporalis fascia alone as graft material. 25 individuals (39.44\%) underwent surgery by using temporalis fascia along with conchal cartilage.

The usage of graft material and size of perforation had a correlation in the present study [12]. Temporalis fascia was used to close small and medium sized perforations. Small perforations of the tympanic membrane was present in 29 cases $(100 \%)$, temporalis fascia alone was used in all of those cases.

In patients with medium perforation of the tympanic membrane, out of a total 26 cases 19 individuals (73.1\%) underwent closure of perforation using temporalis fascia alone and in 7 individuals (26.9\%) temporalis fascia with conchal cartilage was used as graft material.

In a study done by Ramagiri Vijay Kumar [11] participants were split into 3 groups of 20 patients in each group. Grouping of patients were based on graft material used, i.e. temporalis fascia, tragal perichondrium and ear lobule fat graft into group A, B and $\mathrm{C}$ respectively

Pre-operative hearing: In a total study population of 75 individuals, the participants were divided into group

\section{Original Research Article}

A and group B based on usage of graft material to repair the tympanic membrane perforation. Patients in Group A underwent type-I tympanoplasty with temporalis fascia used as graft material, in Group B patients were operated with conchal cartilage and fascia used as graft.

The pre-operative hearing in $\mathrm{dB}$ was noted for all participants before surgery. The maximum number of participants i.e. 27 patients $(36 \%)$ had a pre-operative hearing loss of 21-30 dB. The least number was 5 patients $(6.66 \%)$, who had a pre-operative hearing loss of 51-60 dB.

In group $\mathrm{A}$, the total number of participants were 50 individuals (66.7\%) who underwent surgery using temporalis fascia as graft. In that group, the mean preoperative hearing was $26.9 \mathrm{~dB}$. In group $\mathrm{B}$, where conchal cartilage with fascia was used as graft material, the mean pre-operative hearing was $42.7 \mathrm{~dB}$.

In a study done by Kshitij Patil [1], the mean preoperative hearing loss was found to be maximum for cases with total perforations which were $49.15 \pm 7.34 \mathrm{~dB}$, followed by subtotal perforations of $35.38 \pm 10.10 \mathrm{~dB}$ and for large perforations it was $31.73 \pm 9.84 \mathrm{~dB}$. The overall mean pre-operative hearing loss was $34.72 \pm 10.4$ $\mathrm{dB}$.

Post-operative hearing: In the present study, group A participants who underwent type- 1 tympanoplasty using temporalis fascia as graft, the highest improvement in post-operative hearing was $21-25 \mathrm{~dB}$ observed in 2 patients. In the same group, the greatest number of participants with hearing improvement was 26 patients (74.3\%), with a hearing improvement of $11-15 \mathrm{~dB}$.

In group B conchal cartilage with fascia was used as graft material. Here, the highest improvement in postoperative hearing was observed in 9 patients $(25.7 \%)$ with hearing improvement of 11-15 dB. The most number of participants with hearing improvement was 11 patients $(61.1 \%)$ with a hearing improvement of 6-10 dB.

In a study done by Gaurav Batni [9], in which type-1 tympanoplasty was performed on 100 patients. The mean pre-operative air conduction was $38.47 \pm 11.25 \mathrm{~dB}$. The mean post-operative air conduction was $23.92 \pm 13.80 \mathrm{~dB}$. Mean air bone gap pre-operatively was $23.55 \pm 7.56 \mathrm{~dB}$ and post operatively was $11.60 \pm 7.70 \mathrm{~dB}$.

In a study done by Sharan kumar Shetty [10], 50 cases ofchronic suppurative otitis media with tubotympanic disease were used as participants. 
The mean pre-operative hearing loss was $42.50 \mathrm{~dB}$ and mean post-operative hearing was $20.41 \mathrm{~dB}$. In a study done by Mallikarjun S. Tegnoor [13], 50 patients underwent type-1 tympanoplasty. The mean preoperative hearing was $33.34 \mathrm{~dB}$ and mean postoperative hearing was $20.20 \mathrm{~dB}$ with a mean audiological improvement of around $13 \mathrm{~dB}$. The best mean hearing gain was $14.64 \mathrm{~dB}$ in age group of 24-34 years, while lesser gains are noted in 38-50 years age group.

\section{Conclusion}

1. Small perforation of the tympanic membrane is more common $(38.6 \%)$

2. Small and medium perforations can be repaired better using temporalis fascia alone than conchal cartilage with fascia

3. Post-operative Hearing improvement is comparatively better when temporalis fascia is used alone $(14.0 \mathrm{~dB})$

4. Conchal cartilage is better in repair of large and subtotal perforations but hearing improvement postoperatively is comparatively less $(33.7 \mathrm{~dB})$

Thus, from this study it can be concluded that repair of tympanic membrane perforations should be decided on size of perforation and appropriate grafting material. Small and medium perforations are best repaired using temporalis fascia alone which gives the best hearing improvement and large, subtotal perforations can be repaired using conchal cartilage and fascia but hearing improvement would be comparatively low.

\section{What the study adds to the existing knowledge?}

This study adds knowledge of graft-based hearing improvement apart from graft takeup and healing.

\section{Author's contribution}

Dr. A. Dayananad: Concept, monitoring, publication

Dr. B. Harshavardhan: Principle investigator-collect data and interpretation, statistical analysis.

Dr. J. Dheebika: Co-investigator - examination and investigation of patients, editing, IHEC submission.

Dr. S. Palaninathan: Concept, design.

Funding: Nil, Conflict of interest: Nil

Permission from IRB: Yes

Ethical Approval: This study was approved by the Institutional Ethics Committee

\section{Reference}

1. Patil K, Baisakhiya N, Deshmukh PT. Evaluation of different graft material in type 1 tympanoplasty. Indian J Otol. 2014;20 (3):106-114. doi: 10.4103/0971-7749. 136844.

2. Sarkar S. A review on the history of tympanoplasty. Indian J Otolaryngol Head Neck Surg. 2013;65(Suppl 3):455-60. doi: 10.1007/s12070-012-0534-5. Epub 2012 Mar 22.

3. Harris JP, Wong YT, Yang TH, Miller M, How I do it: Anterior pull-through tympanoplasty for anterior eardrum perforations. Acta Otolaryngol. 2016;136 (4):414-419. doi: 10.3109/00016489. 2016. 1139744. Epub 2016 Mar 18.

4. Mathai J. Myringoplasty with temporalis fascia: Analysis of 200 cases. Indian J Otolaryngol Head Neck Surg. 1999;51(2):9-13. doi: 10.1007/BF02997983.

5. Heermann J, Heermann H, Kopstein E. Fascia and cartilage palisade tympanoplasty: Nine years' experience. Arch Otolaryngol. 1970; 91(3):228-241. doi:10.1001/archotol.1970.00770040334004.

6. Gerber MJ, Mason JC, Lambert PR. Hearing results after primary cartilage tympanoplasty. Laryngoscope. 2000;110 (12):1994-1999. doi: 10.1097/00005537200012000-00002

7. Yung M. Cartilage tympanoplasty: literature review. J Laryngol Otol. 2008;122(7):663-672. doi: 10.1017 /S0022215108001813. Epub 2008 Mar 3.

8. Nemade SV, Dabholkar JP. Healing and hearing results of temporalis fascia graft Vs cartilage graft (Full thickness and half thickness) in type I tympanoplasty. Online J Otolaryngol. 2014;4(3):1-20.

9. Batni G, Goyal R. Hearing outcome after type I tympanoplasty: a retrospective study. Indian J Otolaryngol Head Neck Sur. 2015;67(1):39-42. doi: 10.1007/s12070-014-0749-8.

10. Shetty S. Pre-operative and post-operative assessment of hearing following tympanoplasty. Indian J Otolaryngol Head Neck Surg. 2012;64(4):377-381. doi: 10.1007/s12070-011-0331-6.

11. Kumar RV, Ramakrishnaiah P, Radha Krishna N, Indira S. Outcome of different graft materials used in Myringoplasty. IAIM. 2016;3(2):119-128. 
12. PIMS I, Awan Z. Myringoplasty: a comparative study of different graft materials and various surgical techniques. Ann. Pak. Inst. Med. Sci. 2008;4(4):209211.
13. Tegnoor MS, Ali K, Mithun S. Audiometric evaluation of type 1 tympanoplasty for hearing results. Int J Otorhinolar

\section{...............................}

How to cite this article?

A. Dayanand, B. Harshavardhan, J. Dheebika, S. Palaninathan. Study on temporalis fascia graft versus temporalis fascia with cartilage graft. Trop J Ophthalmol Otolaryngol.2019; 4(6):380-387. doi:10.17511/jooo.2019.i06.05 